\title{
Effect of Non-uniform Corrosion on the mechanical properties of corroded steal bars
}

\author{
Yuan Gao', Chunhua $\mathrm{Lu}^{2}$, Siqi Yuan ${ }^{3}$, Jinmu Yang ${ }^{4}$ \\ ${ }^{1}$ Jiangsu University \\ Zhenjiang, Jiangsu, China \\ e-mail: $1045317009 @ q q . c o m$ \\ ${ }^{2}$ Jiangsu University \\ Zhenjiang, Jiangsu, China \\ e-mail: 1ch79@mail.ujs.edu.cn \\ ${ }^{3}$ Jiangsu University \\ Zhenjiang, Jiangsu, China \\ e-mail: 452281800@qq.com \\ ${ }^{4}$ Jiangsu University \\ Zhenjiang, Jiangsu, China \\ e-mail: 1320109113@qq.com
}

Keywords: drying-wetting cycles experiment; corroded steal bars; non-uniform coefficient; mechanical performance; additional bending moment

\begin{abstract}
In order to accurately study the mechanical performance of corroded steel bars, chlorine salt drying-wetting cycles experiment for pre-cracked concrete specimens is carried on for 4 years. Based on notch depth measurement and tensile test, the non-uniform coefficient and the mechanical of corroded reinforcement from cracked concrete specimens have been researched. Following conclusions can be concluded: (1) Significant localized corrosion can be observed for reinforcement around cracked areas, slight uniform corrosion occurs for reinforcement in sound concrete; (2) The non-uniform coefficient increases with the increase of corrosion rate as the corrosion rate between $3 \%$ to $5 \%$; (3) Based on the existing literature data, mathematical model for $16 \mathrm{~mm}$ diameter steel bars has been built to predict corroded rebar mechanical properties; (4) Researching the impact of the corrosion nonuniformity on the ductility of steel bar, it is indicated that the main reason which cause the plasticity reduced and the yield platform disappeared is the nonuniformity of corrosion. It leads to the tensile with eccentricity and produce the additional bending moment, thus making for the brittle fracture of corroded reinforcement.
\end{abstract}

\section{Introduction}

For coastal concrete structure, steel corrosion caused by chloride ion erosion is the main reason of this kind of 
structure durability failure ${ }^{[1,2]}$. When corrosion seriously, it even leads to brittle failure of component, the overall collapse of structure and other serious consequences. Therefore, studying the mechanical properties degradation characteristics of reinforcement after corrosion is of great significance to predict the structure durability life.

In recent years, the domestic and foreign scholars have studied on the corroded reinforced mechanical performance degradation process and some analysis models have been put forward. These component for studies mainly be taken from the experiment of artificial climate acceleration, galvanostatic acceleration corrosion test and on-site dismantle old member corroded specimens. Such as WU Qing ${ }^{[3]}$, XU Gang ${ }^{[4]}$, ZHANG Weiping ${ }^{[5]}$, who have studied on the models of corroded reinforced degradation under natural environment. While ZHANG Weiping ${ }^{[6]}$, AN Lin ${ }^{[7]}$, LI Fenglian ${ }^{[8]}$, and others have studied on the reinforcement mechanics performance of uniform corrosion by electricity to accelerate. Francois ${ }^{[9]}$, Almusallam ${ }^{[10]}$,etc, through the experimental study confirmed that the nominal strength decreases with the increase of corrosion rate estimating by the initial sectional area of steel bar. But it is almost not changed with the corrosion rate calculating by the actual sectional area after corrosion. The reason may be that corrosion will not change the microstructure of the rebar ${ }^{[11-15]}$. Most of the existing models of steel mechanical performance are described with loss rate of mass or cross section. However the strength analysis models of the corroded reinforced degradation are quite different. One of the most important reason is that the source of the corroded rebars varies considerably, which may be influenced by erosion environment, corrosion test method, and steel corrosion morphology. In addition, the existing empirical formula is generally based on the uniform corrosion. But in the actual project, the structural members work mostly with cracks, and corrosion of steel generally presents pitting corrosion. While from an overall perspective of the structural durability, compared with the strength, the reduced ductility caused by steel reinforcement corrosion, which resulting in brittle fracture of members is more serious.

Based on the above considerations, in this paper an chloride salt drying-wetting cycles experiment in natural environment is carried for about four years to study the characteristics of reinforcement corrosion members in pre-cracked concrete. At the same time the existing empirical models were analyzed to explore. Finally we focus on the impact of the non-uniform corrosion on the ductility of steel reinforcement and analyze the main reasons causing the yield platform disappeared.

\section{Experimental programs}

In the test the samples are obtained by the chloride salt drying-wetting cycles experiment in natural environment. The size of reinforced concrete prism specimens used in the test is $150 \mathrm{~mm} \times$ $100 \mathrm{~mm} \times 1500 \mathrm{~mm}$, as shown in Fig1. In materials, it is including 42.5 Portland cement, coarse aggregate of particle size $5 \sim 25 \mathrm{~mm}$ gravel, fine aggregate fineness modulus of 1.62 natural river sand, tap water. And the ratio of cement: water: sand: stone is 1: $0.43: 1.25: 2.91$. The standard cube compressive strength for 
$28 \mathrm{~d}$ is $32.1 \mathrm{MPa}$. Each member is configured of two $16 \mathrm{~mm}$ diameter HRB335 rebars, with $20 \mathrm{~mm}$ and $40 \mathrm{~mm}$ thicknesses protective layer respectively. The reason for the pre-cracks is, on one hand, simulating the actual project structure stress cracking state. On the other hand it is good for accelerating corrosion. Thus during pouring members, a metal sheet in the reserve component surface is used at different depths, widths, crack spacing, the fracture parameters as shown in Table 2, in which the crack spacing refer to common crack spacing of the bending member in the actual engineering $(150 \mathrm{~mm} \sim 250 \mathrm{~mm})$.
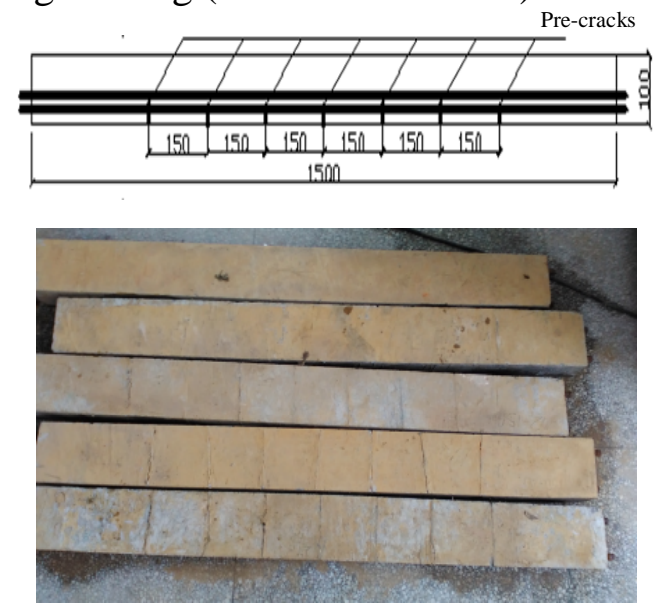

Fig 1 Reinforced concrete specimens

Table 1 Specimens used for experiment

\begin{tabular}{cccc}
\hline $\begin{array}{c}\text { Sam- } \\
\text { ple }\end{array}$ & Specimens & $\begin{array}{c}\text { Reinforc- } \\
\text { ement } \\
\text { Number }\end{array}$ & $\begin{array}{c}\text { Concrete } \\
\text { cover } \\
\text { thickness } \\
\text { /mm }\end{array}$ \\
\hline \multirow{2}{*}{1} & \multirow{2}{*}{ Sound } & $1-1$ & 20 \\
& & $1-2$ & 40 \\
2 & $02-250-40$ & $2-1$ & 20 \\
3 & & $2-2$ & 40 \\
& & $3-1$ & 20 \\
4 & $02-150-40$ & $3-2$ & 40 \\
& & $4-1$ & 20 \\
5 & $02-150-20$ & $4-2$ & 40 \\
& & $5-1$ & 20 \\
\hline
\end{tabular}

After about four years experiment, the steel samples were removed by breaking the specimens. According to the distribution of corrosion intercepted the reinforced steel. There were total 30 samples and the length of each sample was $500 \mathrm{~mm}$. According to the rust treatment method in ASTM G1-03 ${ }^{[16]}$, firstly, clean the steel at a concentration of $5 \% \mathrm{HCl}$ solution at room temperature for about 10 mins. If necessary, rust with a wire brush. Secondly, clean the residual stains by anhydrous ethanol. Finally, dry the reinforced. The states of steel before and after rusting are shown Fig 2.
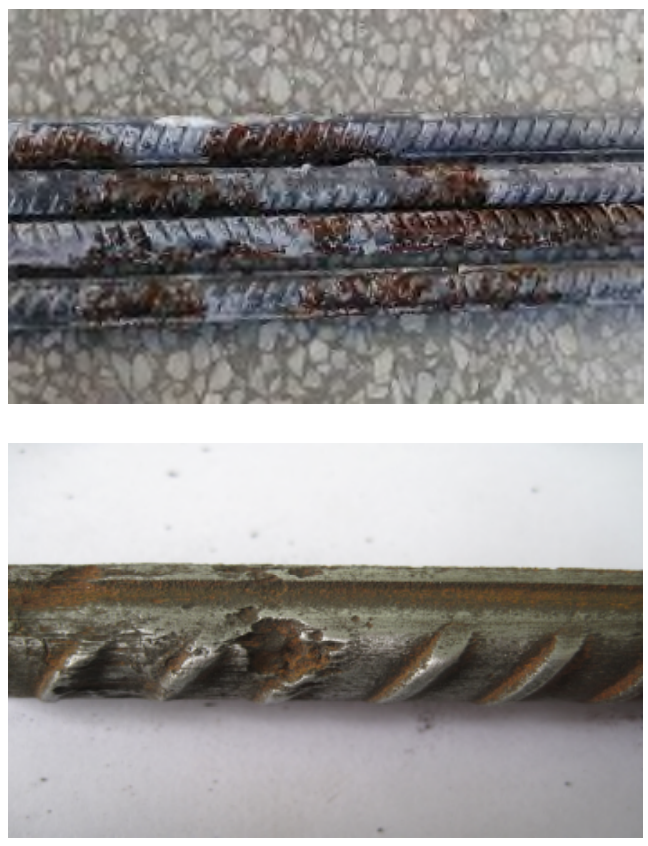

Fig.2 Specimens of corroded steel bars

\section{Results and Analysis}

\subsection{The effects of cracks on the steel corrosion nonuniformity}



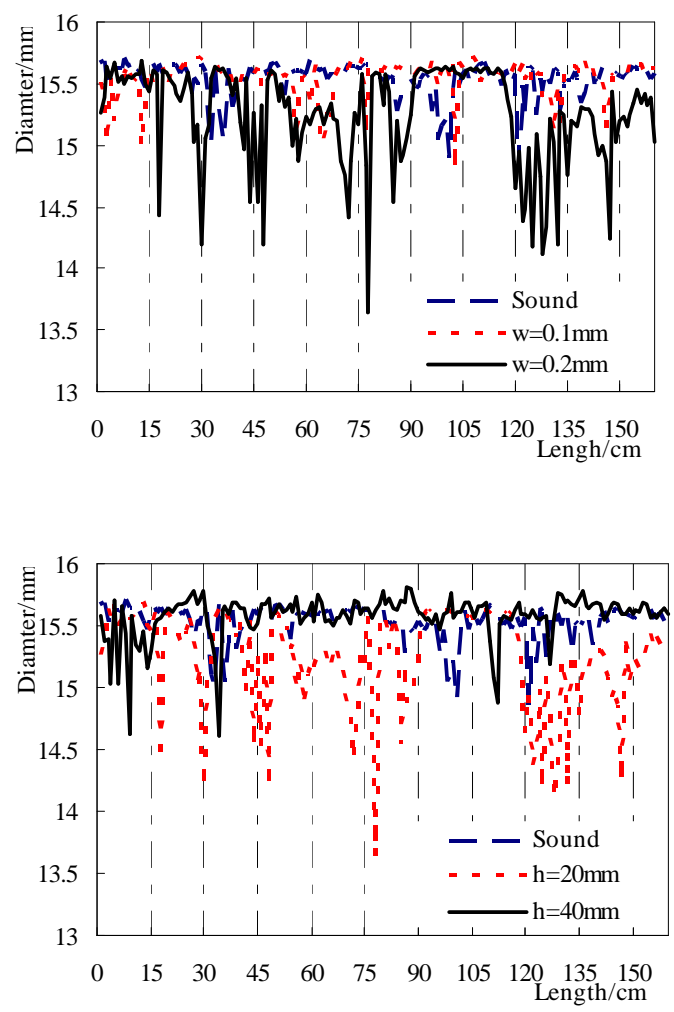

Fig.3 Variation of steel bar's diameter

The surplus diameter distribution of corroded reinforced were collected by a micrometer whose accuracy is $0.001 \mathrm{~mm}$, the results (in Fig3 the dotted line represents a crack position) as shown in Figure 3. As it can be seen from Fig.3, with the crack width increasing, there is a significant increase in bar diameter loss. For the impact of crack depth, as the cracks do not penetrate to the steel, steel corrosion present unevenness obviously, while it tends to uniform corrosion when the cracks run through the reinforced steel. This is due to the presence of cracks which provide a rapid passage for chlorine ions and other aggressive medium through the cracks. When the cracks run through the reinforced steel, the medium erosion along cracks invade to the interior reinforced, thus increasing the corrosion area of the reinforcement. While steel corrosion in crack area is a typical local corrosion, which has a micro cell and macro-cell corrosion coexistence features. Thus, corrosion strength increases, eventually leading to non-uniform corrosion of reinforcement in the longitudinal direction.

\subsection{The non-uniform coefficient}

In order to investigate the longitudinal non-uniformity of corrosion steel, in this paper, the ratio of the maximum loss rate of the rebar diameter and the average loss rate of the rebar diameter is used as the non-uniform coefficient $S$ of corrosion steel to descript the steel corrosion unevenness in the longitudinal extent.

$$
S=\frac{\rho_{\max }}{\rho_{\text {avg }}}
$$

Wherein, $\rho_{\max }$ is the maximum loss rate of the rebar diameter $(\%) . \rho_{\text {avg }}$ is the average loss rate of the rebar diameter $(\%)$, calculated by the gravimetric method.

The average corrosion rate of the test bars are ranging from $3 \%$ to $5 \%$ in this paper. Within this ', the non-uniform coefficient $S$ is linear with the maximum loss rate of diameter $\rho_{\max }$, whose linear fit coefficient of determination $R^{2}$ reaches 0.9366 . The $S$ increases with the average corrosion rate (ie the rate of mass loss) also gradually, as shown in Fig4. It is note that for the non-uniform corrosion of steel, the influence of the maximum pit depth is relatively significant. 

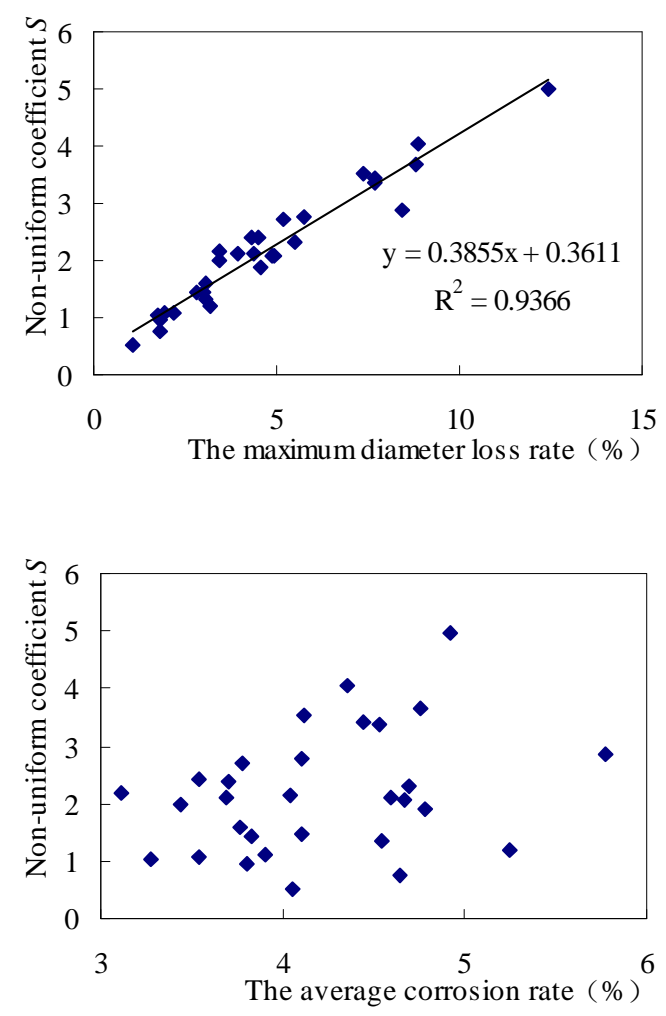

Fig.4 The non-uniform coefficient of corroded steel bars

\subsection{Mechanical properties of uneven corroded reinforced under chloride erosion in nature}

\subsubsection{The strength model of heterogeneity corrosion}

Currently, there are a large number of domestic and foreign scholars based on experimental study of corroded reinforced have proposed the empirical formula of the nominal yield strength, ultimate strength and elongation on behalf of the corrosion rate, as shown in Table 2. Such as, HUI Yunling ${ }^{[11]}$ who has made corroded reinforcement mechanical properties testing from components service for about twenty years with varying corrosion degrees and microstructure analysis, but there were no distinguish between steel grades and sizes, thus representing discrete data. Wang Junqiang ${ }^{[18]}$ considered the impact of steel grades and carried out experimental study on mechanical properties of grade I and grade II . Ma Liangzhe ${ }^{[19]}$, who for the first time considered the size of the bar diameter, made experimental study separately for different diameter levels of different steels. Zhang Weiping et al. ${ }^{[5,17,20]}$ considered different mechanical properties of different corrosion state, studied mechanical properties of the replaced members from the scene, naturally bare steels and powered acceleration performance. WU Qing ${ }^{[3]}$, who studied on the mechanical properties of the corrosion steels obtained by the simulation of artificial climate accelerated corroded and the constant current corroded methods. Sun Xiaoyan et $\mathrm{al}^{[12]}$ also used the existing experimental data to fit the model to predict the mechanical properties of steel.

Table. 2 Formulas corroded reinforcement mechanical performance

\begin{tabular}{cc}
\hline $\begin{array}{c}\text { Mechanical performance } \\
\text { degradation model }\end{array}$ & References \\
\hline$\partial_{y}=0.985-1.028 \eta$ & \\
$\partial_{u}=0.986-1.103 \eta$ & HUI Yunling ${ }^{[11]}$ \\
$\partial_{\delta}=(0.85-\eta)^{2}$ & \\
$\partial_{y}=1-2.4 \eta$ & WANG $^{[18]}$ \\
$\partial_{u}=1-1.3 \eta$ & Junqiang $^{[18]}$ \\
$\partial_{\delta}=1-2.25 \eta$ & MA \\
$\partial_{y}=1-0.557 \eta$ & Liangzhe $^{[19]}$ \\
\hline
\end{tabular}


continued Table. 2

$\begin{array}{cc}\partial_{u}=1-0.639 \eta & \text { MA } \\ \partial_{\delta}=1-0.0536 \eta^{0.656} & \text { Liangzhe }^{[19]} \\ \partial_{y}=1-1.049 \eta & \\ \partial_{u}=1-1.119 \eta & \text { ZHANG } \\ \partial_{\delta}=e^{-2.501 \eta} & \text { Weiping }^{[5,17,20]} \\ \partial_{y}=1.175-6.4 \eta & \\ \partial_{u}=1.18-6.2 \eta & \\ \partial_{\delta}=1-5.75 \eta & \\ \partial_{y}=1-1.009 \eta & \\ \partial_{u}=1-1.158 \eta & \\ \partial_{\delta}=e^{-2.707 \eta} & \\ \partial_{y}=0.9759-0.7238 \eta & \\ \partial_{u}=0.9645-0.7729 \eta & \text { SUN Qing }^{[3]} \\ & \\ & \\ & \\ & \end{array}$

In fact, from the perspective of the whole economic life durability of structure, the early benefits of consolidation and maintenance are more important. Therefore, this article focuses on the performance of corroded reinforced research with the amount of corrosion within $20 \%$.

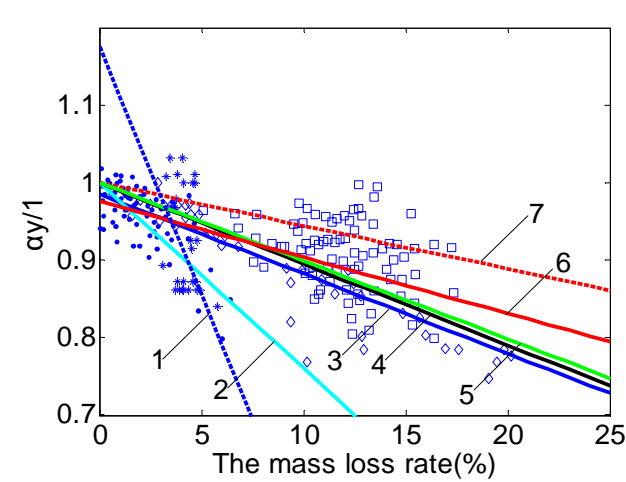

(a) Nominal yield strength

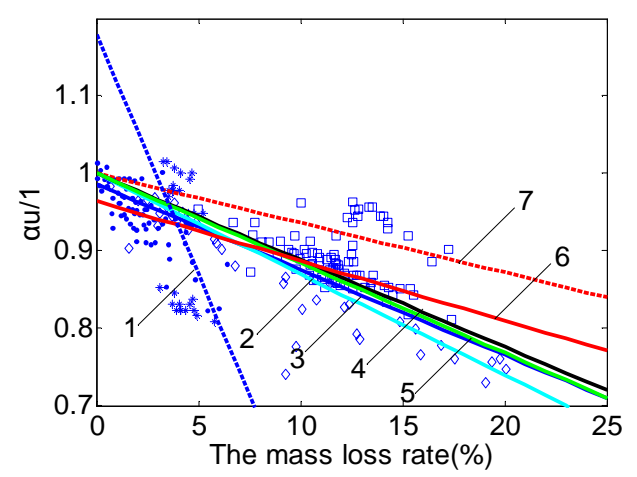

(b) Nominal ultimate strength

注: 1-literature[3]; 2- literature [19]; 3-

literature [11]; 4- literature [17]; 5- literature

[12]; 6-This paper; 7- literature [20]。

Fig.5 Strength degradation models of corroded steel bars

To verify the usefulness of the above empirical formula, we considered the impact of steel grade and diameter, and carried out a test with $16 \mathrm{~mm}$ diameter HRB335 (II grade). At the same time we learned from $\mathrm{Xu} \mathrm{Gang}^{[4]}$, Ma Liangzhe $^{[19]}$, Wang Junqiang [18] and others experimental data of the same type of bar totally 225 data points. Then an empirical model is fitted based on the existing data points. In this paper, the resulting degradation model is fitted with similar model in the literature [19] which also considers the influence of the bar diameter degradation. 
As shown in Figure 5, there are differences between the empirical formulas, which mainly due to differences in test conditions and reinforced specimen size and grade. Even considering the same level and type of reinforced under natural erosion environment, experimental data still has a large discrete. Thus we consider the degree of degradation of the mechanical properties of corroded reinforced not only affected by the rate of corrosion. The state of corroded steel is one of the main factors of the degradation of the steel mechanical properties.

\subsubsection{Effects of heterogeneity on corroded steel strength}

In order to investigate the effect of heterogeneity on the strength of corroded reinforced steel corrosion, in this paper several groups of substantially the same corrosion rate steel sample are selected for comparison. It is found that the relative value of the yield strength and the ultimate strength of steel significantly decreased with the corrosion uneven levels increased, as shown in Fig 6 . When the corrosion rate of about $3 \%$, the steel corroded heterogeneity is relatively small, yield strength and ultimate strength do not significantly reduce. But when the corrosion rate of about $5 \%$, steel uneven corrosion degree is remarkable, as the uniformity coefficient of rust increasing the yield strength and ultimate strength relative value decrease by about $20 \%$. This is due to under chloride corrosion environment, especially in the case of cracking members, the steel is mainly pitting corrosion, where may appear stress concentration. The stress concentration related to the pit depth, will result in the destruction of reinforced advance. Thus, the degree of degradation of the mechanical properties of corroded reinforced is not only influenced by the corrosion rate, the non-uniformity of steel corrosion should be taken into account also.

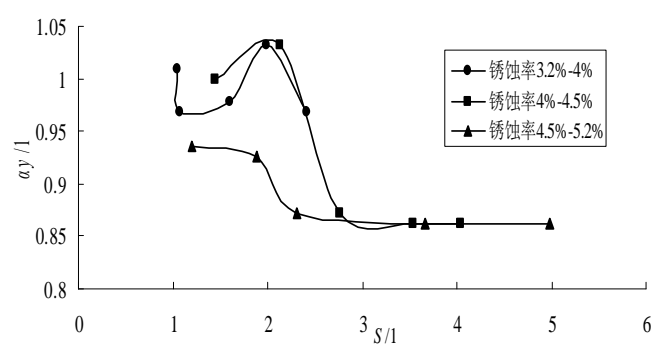

(a) Nominal yield strength

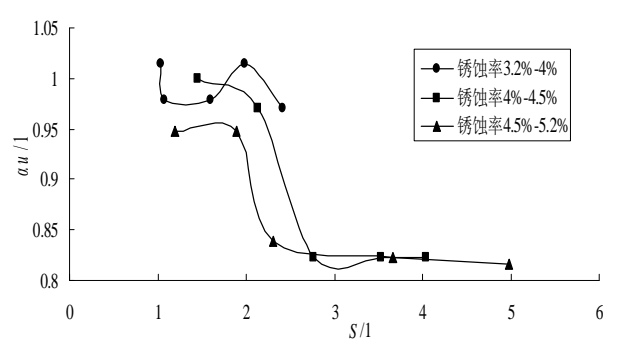

(b) Nominal ultimate strength

Fig.6 Variations of the corroded reinforcement mechanical properties

\subsubsection{Effects of heterogeneity on the ductility of corrosion steel}

As shown in Table 2 compared to strength degradation model, each empirical model of steel ultimate elongation is significant different, mainly due to larger discrete experimental data. It is mainly because the difference between the experimental conditions leading to the discrete nature of the data on the one hand. On the other hand, the reason is the unevenness of steel corrosion. As shown in Fig. 7, the steel elongation relative value differs greatly in nearly the same corrosion rate of about $5 \%$. Therefore, in this article it is proposed that not only the impact of the 
rate of corrosion should be considered to reduce the elongation, effects of heterogeneity also be accounted for a major role.

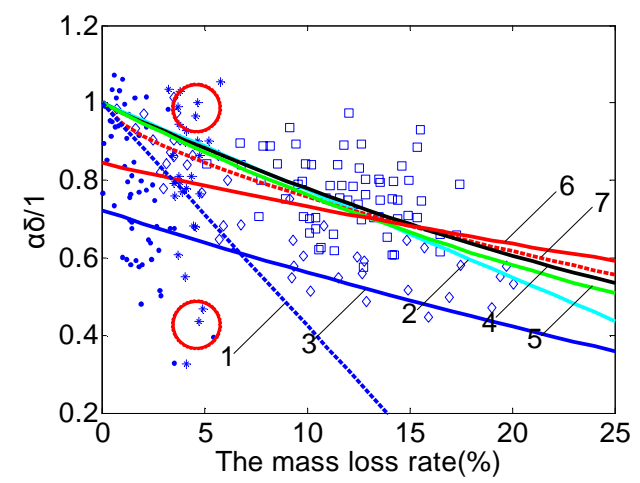

Fig.6 Elongation degradation models of corroded steel bars

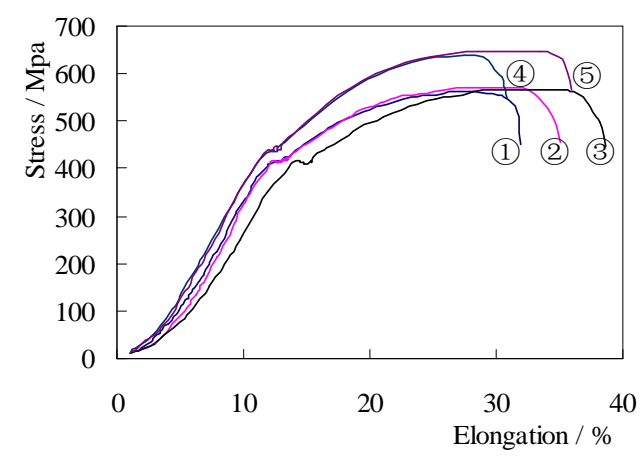

(a)The uniform corrosion

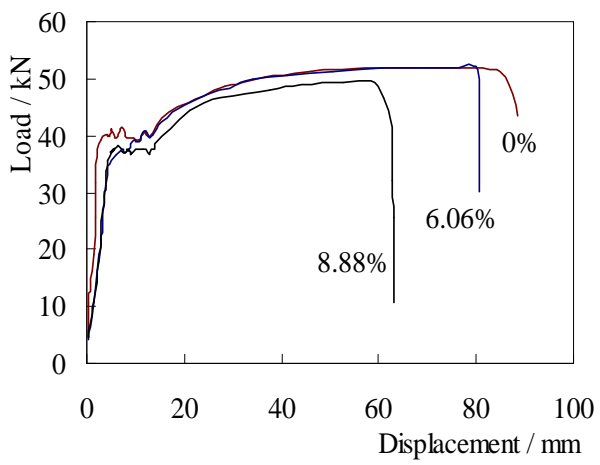

(a) The non-uniform

Note: (1): $\eta=4.36 \%, S=4.0386$; (2): $\eta=4.703 \%$, $S=2.3044$; (3): $\eta=4.55 \%, S=1.3389$; (4): $\eta=4.44 \%, S=3.4258$; (5): $\eta=4.76 \%, S=3.667$;

Fig.7 Constitutive relation of corroded reinforcement

Compared with each reinforced constitutive relation curves under different non-uniform coefficient of rust in natural and even corroded steel constitutive relationship curves, here analyzed the main reasons causing yield point elongation disappear. As shown in Fig. 7 (a), under the same corrosion rate, the yield point elongation is disappearing with the non-uniform coefficient increasing. When the uniformity coefficient $S>4$, the yield platform almost disappeared and the ultimate elongation decreased, thus leading to lower the reinforced plastic and the raising risk of brittle fracture. At the same time literature[8] gives uniform corrosion, under the corrosion rate of less than $10 \%$ the steel steal have obvious yield platform, as shown in fig7 (b). It is indicated that the initial reason causing the decrease of the plastic and the disappearance of the yield platform steel corrosion is mainly due to the non-uniformity corrosion. The greater the steel corrosion longitudinal non-uniform coefficient, the greater the centroid offsets of the cross section with the maximum loss rate of bar diameter, it results the reinforced to withstand the pull effect in partial, and results in the larger additional moment, making the risk of the steel brittle fracture increasing. In this paper, the conclusions are consistent with that in literature [21] witch studied on the effects of the corroded reinforced steel cross-sectional shape on the ductility. It is found that the reinforced bars withstand the action of pulling caused by the asymmetric cross section centroid offsets and then occurs the brittle failure.

\section{Conclusions}

(1) Studying on the reinforced concrete 
structures with cracks, it is found that good reinforcement member can be regarded as uniform corrosion. But the heterogeneity of corrosion steel is obvious when the crack width greater than $0.2 \mathrm{~mm}$, and the maximum diameter loss occurs near the fissure. When the cracks do not penetrate to the depth of steel, reinforced steels present an uneven corrosion, while it tends to uniform corrosion as cracks run through the reinforced steel.

(2) In this paper the impact bar size is considered, the degradation model of $16 \mathrm{~mm}$ diameter HRB335 (II level) reinforced is established, and reference the literature $[4,18,19]$ data to fit the reinforced mechanical degradation empirical formula. The formula is similar to that in the literature [18]. Because of the stress concentration, the degree of degradation of the mechanical properties of corroded reinforced is not only influenced by the corrosion rate, the non-uniformity of steel corrosion should be taken into account also

(3) It is indicted the reason that led to the decrease of the reinforced plastic and the disappearance of the yield plateform is mainly due to the longitudinal non-uniformity of corrosion. When the non-uniform coefficient is large enough $S>4$, the yield platform almost disappears. It is because the heterogeneity of corrosion result in the centroid offsets, making the steel withstand the action of partial pulling and exist additional moment, thus leading to the brittle failure of structures.

\section{References}

[1] Du YG, Clark LA, Chan AHC. Residual capacity of corroded reinforcing bars[J]. Magazine of
Concrete

Research, 2005,57(3):135-147.

[2] JIN Wei-liang, YUAN Yingshu, WEI Jun et al. Durability theory and design methods of concrete structures under chloride environment[M]. Beijing: Science Press, 2011:1-17.(in Chinese)

[3] WU Qin, YUAN Ying-shu. Experimental study on the deterioration of mechanical properties of corroded steel bars[J].China Civil Engineering Journal,2008,41(12):42-47.(in Chinese)

[4] XU Gang, ZHANG Dong, LIU De-fu, et al. Research on mechanical properties of corroded steel bar in concrete under chloride environment[J]. SHUILI XUEBAO,2012,43(4):452-459. (in Chinese)

[5] ZHANG Wei-ping, SHANG Deng-feng, GU Xiang-lin. Stress-Strain Relationship of Corroded Steel Bars[J]. Journal of Tongji University (Natural Science),2006,34(5):586-592 . (in Chinese)

[6] ZHANG Wei-ping, WANG Xiao-gang, GU Xiang-lin. Comparative study on structural performance of reinforced concrete beams subjected to natural corrosion and accelerated corrosion[J]. Journal of Southeast University (Natural Science

Edition),2006,36(Sup II ):139-144. (in Chinese)

[7] AN Lin, OU Yang-ping, ZHENG Ya-ming. Effect of stress concentration on mechanical properties of corroded reinforcing steel bars [J]. Journal of Southeast 
University (Natural Science Edition), 2005, 35(6):940-941. (in Chinese)

[8] LI Feng-lan, HOU Wei-ling, HOU Peng-bing. Experimental Study on Mechanical Properties of Corroded Steel Bars[J]. Journal of North China Institute of Water Conservancy and Hydroelectric

Power,2013,34(4):62-64. (in Chinese)

[9] Francois R, Khan I, Dang V H. Impact of corrosion on mechanical properties of steel embedded in 27-year-old corroded reinforced concrete beams $[\mathrm{J}]$. Materials and Structures, 2013, 46(6): 899-910.

[10]Almusallam A A. Effect of degree of corrosion on the properties of reinforcing steel bars [J]. Construction and Building Materials, 2001,15(8): 361-368.

[11]HUI Yun-ling, LIN Zhi-shen, LI Rong. Experimental study and analysis on the property of corroded rebar[J]. Industrial Construction, 1997, 27(6): 10-13. (in Chinese)

[12]SUN Xiao-yan, ZHU Jian-ke, WANG Hai-long, et al. Experimental Investigation of Performance Degradation of Corroded Rebar Considering Pitting Feature $[\mathrm{J}]$. Journal of Building Materials, 2014,17(5):804-810.(in Chinese)

[13]Zhang W P, Song X B, Gu X L, Li S $B$. Tensile and fatigue behavior of corroded rebars $[\mathrm{J}]$. Construction and Building Materials, 2012, 34:409-417.

[14]ZHANG Ping-sheng, LU Mei, LI Xiao-yan. Mechanical property of rustiness reinforcement steel[J]. Industrial Construction, 1995,25(9):41-43. (in Chinese)
[15]Papadopoulos M P, Apostolopoulos C A, Zervaki A D. Corrosion of exposed rebars associated mechanical degradation and correlation with accelerated corrosion tests $[\mathrm{J}]$. Construction and Building Materials, 2011, 25(8): 3367-3374.

[16]Apostolopoulos C A, Papadopoulos M P, Pantelakis S G. Tensile behavior of corroded reinforcing steel bars BSt 500s [J]. Construction and Building Materials, 2006, 20(9):782-789.

[17]ZHANG Wei-ping, LI Chong-kai, GU Xiang-lin, et al. Stochastic Model of Constitutive Relationship for Corroded Steel Bars[J]. Journal of Building Materials, 2014, 17(5):920-925. (in Chinese)

[18]WANG Junqiang. Experimental study and analysis on mechanical properties of corroded reinforcing bars in the atmosphere environment $[\mathrm{J}]$. Journal of Xuzhou Institute of Architectural Technology, 2013,3(3):25-27. (in Chinese)

[19]MA Liangzhe, BAI Changju. Experimental research of mechanical performance of corroded reinforcement $[\mathrm{C}] / /$ The fifth session of the national academic seminar on the durability of concrete. Beijing: China Architecture Building Press, 2000:112-118. (in Chinese)

[20]ZHANG Wei-ping, SHANG Dengf-eng, GU Xiang-lin. Sate-of-the-art of the mechanical properties of corroded steel bars[J]. Industrial Construction, 2005(S1):706-709. (in Chinese)

[21]Wenjun Zhu, Raoul Francois. Experimental investigation of the relationships between residual 
cross-section shapes and the Construction and Building Materials, ductility of corroded bars[J]. 2014, 69:335-349. 